\title{
Daily Variation in the Occurrence of Different Subtypes of Stroke
}

\author{
Luciana Ripamonti, ${ }^{1}$ Roberto Riva, ${ }^{1,2}$ Fabiola Maioli, ${ }^{3}$ \\ Corrado Zenesini, ${ }^{1}$ and Gaetano Procaccianti ${ }^{1}$ \\ ${ }^{1}$ IRCCS Institute of Neurological Sciences, Bologna, Italy \\ ${ }^{2}$ Department of Biomedical and Neuromotor Sciences, University of Bologna, Bologna, Italy \\ ${ }^{3}$ Department of Medicine, Maggiore Hospital, Bologna, Italy
}

Correspondence should be addressed to Roberto Riva; roberto.riva@unibo.it

Received 4 April 2017; Accepted 22 May 2017; Published 22 June 2017

Academic Editor: David Vaudry

Copyright (C) 2017 Luciana Ripamonti et al. This is an open access article distributed under the Creative Commons Attribution License, which permits unrestricted use, distribution, and reproduction in any medium, provided the original work is properly cited.

\begin{abstract}
Three thousand two hundred and ninety-eight patients admitted to our Stroke Unit with hemorrhagic, large artery atherosclerosis, cardioembolic, small-vessel occlusion, and undetermined etiology-cryptogenic strokes were included in the study. The circadian variability in onset in each stroke subgroup and the associations with various risk factors were analyzed. In each subgroup, a significant minority of patients suffered from stroke during sleep. In the ischemic group, hypercholesterolemia, paroxysmal atrial fibrillation, and previous myocardial infarction facilitated the onset during waking. During waking, stroke onset was significantly higher in the morning compared to the afternoon both in the hemorrhagic and in the ischemic type. In hemorrhagic stroke, a previous stroke was associated with a lower early morning occurrence. In large artery atherosclerosis stroke, males were at higher risk of early morning occurrence $(p<0.01)$. In small-vessel occlusion stroke, hypertension is significantly more present in the morning compared to the afternoon onset $(p<0.005)$. Circadian patterns of stroke onset were observed both in hemorrhagic and in ischemic stroke, irrespective of the ischemic subgroup. In all groups, stroke was more likely to occur during waking than during sleep and, in the diurnal period, during morning than during afternoon. Moreover, sex and some clinical factors influence the diurnal pattern.
\end{abstract}

\section{Introduction}

Circadian variation in stroke onset has been analyzed since the early 1970s, but until the beginning of the new millennium data were very discordant [1, 2]. In 1998 a meta-analysis [3] revealed a higher frequency of onset stroke in the morning with a lower risk during the night. In the last 20 years other studies have contributed more information especially in highlighting some differences in the various etiological subtypes. However, some data remain discordant [4-31] (see Table 1 for details). Moreover, risk factors have been given little consideration in relation to daily onset in stroke subtypes and mostly without significant results $[4,5,10,17$, 32-37]. However, most authors have not studied the subtype simultaneously or, when done, the number of patients was too small to investigate the difference in circadian onset or the association between circadian rhythms and risk factors in the various stroke subtypes.

The aim of our study was to investigate the circadian characteristics in stroke subtypes. Moreover, we analyzed the association among rhythms and some risk factors.

\section{Patients and Methods}

Our results are based on a retrospective, single-center study of consecutive patients admitted to the Stroke Unit of the Institute for Neurological Disease of Bologna, Italy, over 10 years (January 2004-December 2013). All patients admitted to the Stroke Unit were recruited for the study. The study was approved by the local ethical committee (approval 272/CE, project 16021). The Stroke Unit is situated within the Institute of Neurological Sciences, with a catchment area of about 
TABLE 1: Available evidence on circadian pattern of onset of stroke.

\begin{tabular}{|c|c|c|c|c|c|}
\hline Ref. & Author, year & Country & Cases $(n)$ & Peak & Notes \\
\hline [2] & $\begin{array}{l}\text { Manfredini et al., } \\
2005\end{array}$ & Italy & - & Morning and early evening & Review \\
\hline [3] & Elliott, 1998 & USA & IS, IH, and SAH 11816 & 06:00-12:00 & Meta-analysis \\
\hline$[4]$ & Stergiou et al., 2002 & Greece & $\mathrm{IS}+\mathrm{IH}=811$ & $\begin{array}{c}06: 00-12: 00 \text { and } \\
16: 00-20: 00\end{array}$ & $>50$ and $<81$ yrs \\
\hline$[5]$ & Casetta et al., 2002 & Italy & IS = 1395 & $\begin{array}{c}08: 00-09: 00 \text { and } \\
\text { 20:00-21:00 }\end{array}$ & \\
\hline [6] & Omama et al., 2006 & Japan & $\mathrm{IS}=7575, \mathrm{IH}=3852$ & $\begin{array}{c}\text { IS 06:00-12:00, IH } \\
06: 00-12: 00 \text {, and } \\
16: 00-20: 00 \\
\end{array}$ & \\
\hline [7] & Inagawa et al., 2000 & Japan & $\mathrm{IH}=267$ & Awake & \\
\hline$[8]$ & Butt et al., 2009 & Pakistan & $\mathrm{IS}=438, \mathrm{IH}=329$ & $\begin{array}{c}\text { IS 04:00-08:00 and } \\
\text { 16:00-20:00, IH } \\
08: 00-12: 00\end{array}$ & \\
\hline [9] & Chaturvedi et al., 1999 & USA & $\begin{array}{l}\mathrm{AT}=173 \\
\mathrm{CE}=210 \\
\mathrm{LA}=210\end{array}$ & $\begin{array}{l}\text { AT and CE 06:00-12:00, LA } \\
\text { 12:00-18:00 }\end{array}$ & $\begin{array}{c}\text { The onset more } \\
\text { frequent during sleep } \\
\text { was LA }\end{array}$ \\
\hline$[10]$ & Passero et al., 2000, & Italy & $\mathrm{IH}=901$ & $06: 00-12: 00$ & $\begin{array}{c}\text { Onset peak due to } \\
\text { hypertensive IH }\end{array}$ \\
\hline [11] & Nagakane et al., 2006 & Japan & $\mathrm{IH}=129$ & Awake & \\
\hline$[12]$ & Anderson et al., 2004 & New Zealand & IS and $\mathrm{IH}=1497$ & 06:00-12:00 & \\
\hline [13] & Uddin et al., 2015 & Bangladesh & IS $=50$ & $06: 00-12: 00$ & \\
\hline$[14]$ & Naess et al., 2011 & Norway & $\begin{aligned} \mathrm{AT}=80, \mathrm{CE} & =191, \mathrm{LA}=136 \\
\mathrm{IH} & =662\end{aligned}$ & $\begin{array}{c}\text { LA 00:00-06:00, IH } \\
06: 00-18: 00\end{array}$ & \\
\hline [15] & Lago et al., 1998 & Spain & $\mathrm{LA}=209, \mathrm{CE}=228, \mathrm{AT}=429$ & 09:00-10:00 & \\
\hline$[16]$ & Spengos et al., 2005 & Greece & $\mathrm{IS}=1216, \mathrm{IH}=232$ & & $\begin{array}{c}\text { First-ever stroke } \\
\text { Onset more frequent } \\
\text { during sleep was LA }\end{array}$ \\
\hline$[17]$ & Bornstein et al., 1999 & Israel & IS $=1671$ & Awake & \\
\hline$[18]$ & Cheung et al., 2001 & Hong Kong & $\mathrm{IS}=608, \mathrm{IH}=177$ & $\begin{array}{c}\text { IS 06:00-12:00, IH } \\
06: 00-18: 00 \\
\end{array}$ & \\
\hline$[19]$ & Spengos et al., 2003 & Greece & $\begin{aligned} \mathrm{AT}=171, \mathrm{CE} & =406, \mathrm{LA}=227 \\
\mathrm{IH} & =200\end{aligned}$ & $06: 00-12: 00,16: 00-18: 00$ & \\
\hline [20] & Spengos et al., 2003 & Greece & $\mathrm{CE}=300$ & $\begin{array}{l}08: 00-10: 00 \\
16: 00-18: 00 \\
\end{array}$ & \\
\hline$[21]$ & Turin et al., 2013 & Japan & $\mathrm{IS}=897, \mathrm{IH}=335$ & Awake & \\
\hline$[22]$ & $\begin{array}{c}\text { Jiménez-Conde et al., } \\
2007\end{array}$ & Spain & IS $=813$ & 09:00-12:00 & \\
\hline [23] & Kocer et al., 2005 & Turkey & $\mathrm{IS}=917, \mathrm{IH}=240$ & $\begin{array}{c}\text { IS 03:00-06:00 } \\
\mathrm{IH}, \mathrm{ns}\end{array}$ & \\
\hline [24] & Nyquist et al., 2001 & USA & $\mathrm{IH}=85$ & 08:00-16:00 & \\
\hline$[25]$ & Feng et al., 2011 & USA & $\mathrm{IH}=215$ & $\begin{array}{c}10: 00-12: 00 \text { and } \\
18: 00-20: 00\end{array}$ & \\
\hline$[26]$ & Choi et al., 2015 & Korea & $\mathrm{AT}=256, \mathrm{LA}=276, \mathrm{CE}=155$ & 06:00-12:00 & \\
\hline [27] & Fodor et al., 2014 & Romania & $\mathrm{IS}=969, \mathrm{IH}=94$ & 06:00-12:00 & \\
\hline [28] & Fodor et al., 2014 & Romania & $\mathrm{AT}=60, \mathrm{CE}=153, \mathrm{LA}=538$ & 06:00-12:00 & \\
\hline [29] & Inagawa, 2003 & Japan & $\mathrm{IH}=350$ & $\begin{array}{c}\text { Men }<70 \text { yrs 08:00-10:00 } \\
\text { and 18:00-20:00 } \\
\text { All women or men }>69 \mathrm{yrs} \\
\quad \text { 18:00-20:00 }\end{array}$ & \\
\hline$[30]$ & Serena et al., 2003 & Spain & IS $=1248$ & $06: 00-12: 00$ & \\
\hline
\end{tabular}


TABLE 1: Continued.

\begin{tabular}{|c|c|c|c|c|c|}
\hline Ref. & Author, year & Country & Cases $(n)$ & Peak & Notes \\
\hline [31] & $\begin{array}{l}\text { Bassetti and Aldrich, } \\
1999\end{array}$ & Switzerland & IS $=65$ & 08:00-12:00 & \\
\hline [32] & Turin et al., 2009 & Japan & $\mathrm{IH}=637$ & $\begin{array}{l}\text { 08:00-10:00 and } \\
\text { 20:00-21:00 }\end{array}$ & \\
\hline [33] & Tsementzis et al., 1985 & UK & $\mathrm{IS}=245 \mathrm{IH}=118$ & $10: 00-12: 00$ & All $<70$ yrs \\
\hline [34] & Wroe et al., 1992 & UK & IS $=545$, IH 66 & $\begin{array}{l}\text { 06:00-12:00, IS second } \\
\text { peak at 14:00-16:00 }\end{array}$ & \\
\hline [35] & Sloan et al., 1992 & USA & $\mathrm{IH}=237$ & $\begin{array}{c}10: 00-12: 00 \text {, a second peak } \\
\text { at } 18: 00-20: 00\end{array}$ & \\
\hline [36] & Argentino et al., 1990 & Italy & IS $=426$ & $06: 00-10: 00$ & \\
\hline [38] & Fabbian et al., 2016 & Italy & $\mathrm{CH}=517$ & $\begin{array}{l}\text { Female 08:00-10:00, male } \\
\qquad 12: 00-14: 00\end{array}$ & $\begin{array}{l}\text { Both idiopathic and } \\
\text { posttraumatic } \\
\text { cerebral hemorrhage } \\
\text { were included } \\
\end{array}$ \\
\hline [39] & Marshall, 1977 & UK & Nonembolic IS $=554, \mathrm{IH}=153$ & $\begin{array}{c}\text { IS 00:00-06:00, female IH } \\
06: 00-12: 00\end{array}$ & $\begin{array}{l}\text { Sex difference in time } \\
\text { course } \\
\text { Embolic IS were not } \\
\text { included }\end{array}$ \\
\hline [40] & Caplan et al., 1983 & USA & IS $=127$ & $\begin{array}{l}\text { Asleep in thrombotic and } \\
\text { awake in embolic stroke }\end{array}$ & \\
\hline [41] & $\begin{array}{c}\text { Arboix and } \\
\text { Martí-Vilalta, } 1990\end{array}$ & Spain & $\begin{array}{c}\text { IS = } 142(69 \text { AT, } 45 \mathrm{LA}, 28 \\
\text { CE }) ; \mathrm{IH}=33\end{array}$ & $\begin{array}{c}\text { AT 00:00-00:06, IH } \\
\text { 00:06-12:00 } \\
\text { CE 06:00-18:00, LA ns }\end{array}$ & $\begin{array}{c}\text { Difference in onset } \\
\text { among different } \\
\text { etiologies }\end{array}$ \\
\hline [42] & Hossmann, 1971 & Germany & IS $=131$ & 01:00-05:00 & \\
\hline [43] & Pasqualetti et al., 1990 & Italy & $\mathrm{IS}=508, \mathrm{IH}=159$ & IS morning, IH ns & \\
\hline$[44]$ & Marler et al., 1989 & USA & IS = 1167 & 08:00-10:00 & \\
\hline [45] & Marsh et al. 1990 & USA & IS $=151$ & 06:00-10:00 & \\
\hline$[46]$ & Ricci et al., 1992 & Italy & $\mathrm{IS}=375, \mathrm{IH}=375$ & $06: 00-12: 00$ & $\begin{array}{l}\text { The IS more frequent } \\
\text { during sleep was LA }\end{array}$ \\
\hline
\end{tabular}

$\mathrm{IS}=$ ischemic stroke. $\mathrm{IH}=$ intracerebral hemorrhagic stroke. $\mathrm{AT}=$ large artery atherosclerotic stroke; $\mathrm{CE}=$ cardioembolic stroke; $\mathrm{CRY}=$ cryptogenic stroke; LA = lacunar stroke.

$270,000-320,000$ residents. A consecutive series of 4,560 patients were recruited. The registration form consists of demographic and vital variables, stroke subtype, date and hour of onset, situation at onset, symptoms and clinical findings, family history, history of hypertension, diabetes, hypercholesterolemia, neurological, psychiatric, and cardiovascular disease, use of drugs, functional grade, and clinical evolution. Stroke criteria were defined according to the World Health Organization. Ischemic strokes were classified in line with the TOAST classification. Diagnosis of stroke was made in the presence of rapidly emerging focal or global neurological signs with fast progression, lasting at least $24 \mathrm{~h}$ or leading to death without apparent cause other than a vascular origin. Patients admitted were classified into the following subtypes: large artery atherosclerotic stroke (AT), cardioembolic stroke (CE), lacunar stroke (LA), cryptogenic stroke (CRY), and intracerebral hemorrhagic stroke, other cerebrovascular events or etiology, and transient ischemic attack. Patients with subarachnoid hemorrhage were not admitted to our clinic unit and so they were not recruited for the study.

Stroke onset time was defined as the time at which the patient or a witness first noted clear neurological signs. Determination of the stroke onset time was possible in 3,689 patients. The impairment caused by the stroke was objectively evaluated by the National Institutes of Health Stroke Scale (NIHSS). The degree of disability was measured according to the modified Rankin Score (mRS) [47, 48].

2.1. Statistical Analysis. Continuous variables are presented as mean and standard deviation (SD) while categorical variables as absolute frequency (percentage). ANOVA and chi-square were used to compare variables among subtypes of stroke. The survival curves were estimated with the KaplanMeier method and were compared with log-rank test of equality of survivor functions. Hazard ratios (HR) and 95\% confidence intervals (95\% CI) are presented. Differences in the proportions of stroke during the diurnal period were performed with time of onset divided into three-hour intervals (8-11, 11-14, 14-17, and 17-20) and assessed by the proportion test. Multivariate logistic or univariate linear regressions were performed to study the association between clinical variables and different diurnal period and between awake and asleep onset. On multivariate analyses models, age, gender, previous stroke, hypertension, diabetes mellitus, previous myocardial infarction, hypercholesterolemia, permanent or acute atrial fibrillation, prestroke modified Rankin Score, and admission NIHHS were modelled as independent variables 
while awake/asleep or diurnal time interval were modelled as dependent variables. Odds ratio (OR), slope $(\beta)$, and $95 \%$ $\mathrm{CI}$ are reported when appropriate. Statistical analysis was performed using Statistical Package Stata SE, version 14.0 [49].

\section{Results}

3.1. Population. Data from 4,560 subjects were recorded. Five hundred patients with other cerebrovascular events or etiology and 762 with stroke but with unknown onset time were excluded from the analysis. Our study groups comprised the remaining 3,298 patients with stroke. The principal variables in each subtype are shown in Table 2.

Age and sex did not differ between hemorrhagic and all ischemic strokes, while they significantly differed among ischemic subtypes. As expected, the other clinical variables significantly differed between ischemic and hemorrhagic stroke and among ischemic subgroups.

3.2. Asleep/Awake Onset. At first, we analyzed the distribution of stroke occurrence during sleep and during awake periods. In the sleep period we included patients that became aware of the stroke on awakening in which we did not know the exact hour of onset.

About one-quarter (770 out of 3,298 patients) of stroke patients suffered from stroke during sleep $(p<0.001$ sleep onset versus asleep onset). This pattern was observed in each stroke subgroup (Table 2).

Except for a slightly less seniority in the whole ischemic group with asleep onset compared to awake onset $(\mathrm{OR}=$ $0.98,95 \% \mathrm{CI}=0.97-0.99$ ), no other demographic data were different between awake and asleep onset, while some pathophysiological characteristics modified the awake/asleep onset pattern in some subgroups (Table 3 ). In the whole ischemic group, hypercholesterolemia $(\mathrm{OR}=1.28,95 \% \mathrm{CI}=1.03-1.60)$, paroxysmal atrial fibrillation $(\mathrm{OR}=1.70,95 \% \mathrm{CI}=1.14-2.55)$, and previous myocardial infarction $(\mathrm{OR}=1.38,95 \% \mathrm{CI}=$ 1.03-1.86) facilitated the awake onset. The main differences observed in hypercholesterolemia are substantially related to the CRY subgroup ( $\mathrm{OR}=1.67,95 \% \mathrm{CI} 1.10-2.49)$. On the contrary, in the whole ischemic group, the fact of having had a previous stroke is associated with asleep onset $(\mathrm{OR}=0.77$, $95 \% \mathrm{CI}=0.60-0.99)$. This difference is due to $\mathrm{CE}(\mathrm{OR}=0.62$, $95 \% \mathrm{CI}=0.40-0.98)$ and $\mathrm{LA}(\mathrm{OR}=0.62,95 \% \mathrm{CI}=0.18-0.98)$. Paroxysmal atrial fibrillation is associated with asleep onset in the hemorrhagic group ( $\mathrm{OR}=0.35,95 \% \mathrm{CI}=0.14-0.82)$. No other clinical factor is associated with awake/asleep onset period in other subgroups.

No association of the admission NIHSS and prestroke mRS was observed with awake or asleep onset. The awake/asleep onset period is however associated with different degrees of mRS at hospital discharge in some subgroups. Ischemic stroke showed a worse disability $\operatorname{mRS}(\beta=0.14$, 95\% CI $=0.02-0.26$, and $p=0.032$ ) in asleep onset. This difference is associated with fibrinolysis $(\beta=0.41 \pm 0.10$, $95 \%=\mathrm{CI}=0.21-0.62, p<0.001)$, which was performed in ischemic patients if the hospital arrival time was soon after stroke onset. In these subgroups fibrinolysis was associated with a better discharge mRS $(\beta=0.39,95 \% \mathrm{CI}=0.01-0.778$, and $p=0.047$ in $\mathrm{CE}$ and $0.55,95 \% \mathrm{CI}=0.86-0.23$, and $p=0.001$ in CRY). Hemorrhagic stroke showed a slightly worse disability score at discharge in awake onset $(\beta=0.30$, $95 \% \mathrm{CI}=0.10-0.55$, and $p=0.043$ ) compared to asleep onset. No clinical variables were correlated with these features.

Asleep onset ischemic stroke patients had a 1.33 higher risk of death within the first month of stroke compared to awake onset patients $(\mathrm{HR}=1.33,95 \% \mathrm{CI}=1.04-1.72$, Figure 1(a)). This difference is due to the CE subgroups, in which this risk is 1.55 higher in asleep compared to awake onset $(\mathrm{HR}=1.55,95 \% \mathrm{CI}=1.10-2.19)$ (Figure $2(\mathrm{a}))$. This difference was not associated with fibrinolysis.

No difference in death rate within the first month was observed in hemorrhagic stroke $(\mathrm{HR}=1.18,95 \% \mathrm{CI}=$ $0.79-1.76$, Figure 1(b)) or in the other groups (Figures 2(b), $2(\mathrm{c})$ and $2(\mathrm{~d}))$.

3.3. Diurnal Onset. During the diurnal period stroke onset is significantly more frequent in the morning compared to the afternoon, irrespective of stroke subtype (Figure 3). However, some difference in the patterns can be observed among subtypes: hemorrhagic, LA, and CRY had a more frequent onset in the first part of the morning $(p<0.001)$, while AT had a more frequent onset throughout the whole morning $(p<0.01)$ and CE exhibited a significantly lower frequency of onset in the late morning $(p<0.001)$. Demographic variables and risk factors were associated in a different way with circadian onset in different stroke subtypes (Table 4).

Patients with hemorrhagic stroke in case of at least one previous stroke experienced less frequently the stroke onset in the early morning than during other diurnal periods $(14 \%$ versus $39 \%, \mathrm{OR}=0.15$, and $95 \% \mathrm{CI}=0.04-0.50)$, while hypercholesterolemia was 2.36 times less frequent in the late afternoon (17:00-20:00) onset (11\% versus $26 \%$, OR $=0.33$, and $95 \% \mathrm{CI}=0.14-0.79)$. Sex influenced the time of onset in AT patients $(\mathrm{OR}=2.66,95 \% \mathrm{CI}=1.30-5.44)$ : male patients showed a higher risk and female patients a lower risk for early morning onset compared to afternoon onset.

In LA, arterial blood pressure influenced onset times (OR $=2.25,95 \% \mathrm{CI}=1.30-3.88)$ : hypertensive patients showed a higher onset frequency in the early morning compared to other diurnal times while normotensive patients had almost half of the risk for early morning onset compared to other diurnal periods.

None of the other prognostic variables studied were associated with onset time in other subgroups of stroke.

CRY patients with early morning onset exhibited a slightly better admission NIHSS score compared with other times of onset $(\mathrm{OR}=0.96,95 \% \mathrm{CI}=0.94-0.99$, Table 4$)$.

\section{Discussion}

Our study, including more than 3,000 patients, confirms that both ischemic and hemorrhagic stroke occur preferentially during waking and in certain specific periods of diurnal time in accordance with most authors [1-46] (Table 1). This may depend on pathophysiological factors partially shared by patients with ischemic and hemorrhagic stroke. 


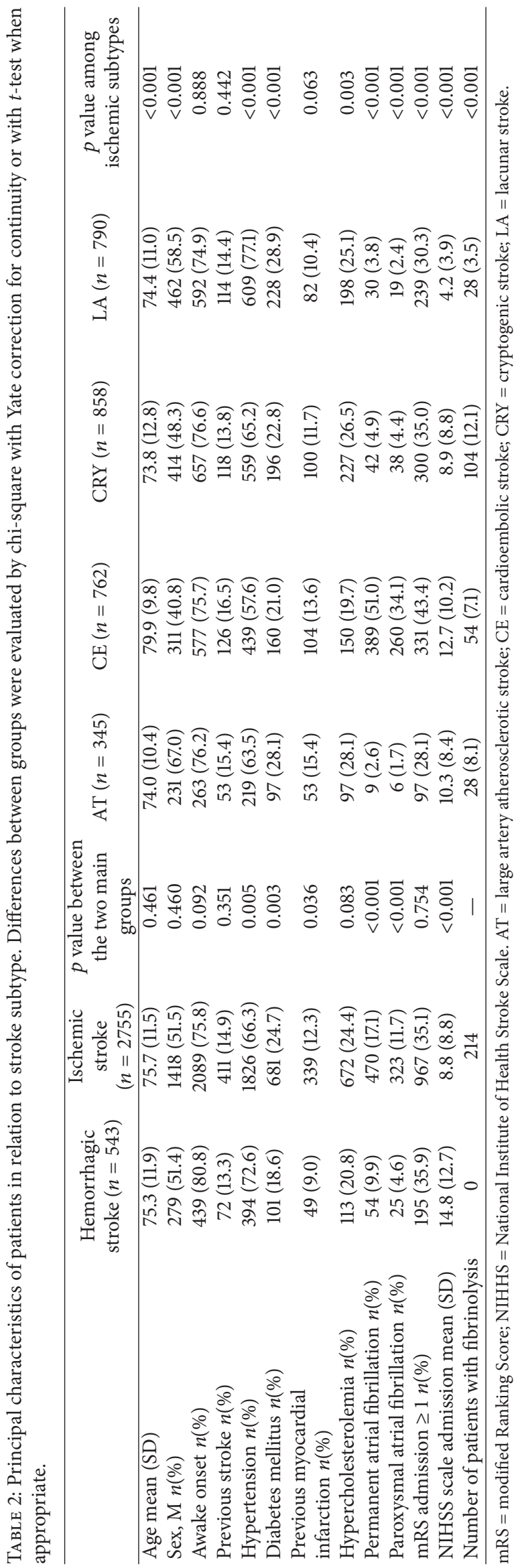


TABLE 3: Multivariate logistic regression between clinical variables (independent variables) and awake/asleep stroke onset (dependent variable).

\begin{tabular}{|c|c|c|c|c|c|c|}
\hline & Hemorrhagic & All ischemic & $\begin{array}{l}\text { CE } \\
\text { OR } 95\end{array}$ & AT & CRY & LA \\
\hline \multirow{2}{*}{ Age } & 0.99 & 0.98 & 0.98 & 0.97 & 0.99 & 0.99 \\
\hline & $0.97-1.01$ & $0.97-0.99$ & $0.96-1.00$ & $0.95-1.00$ & $0.97-1.00$ & $0.98-1.01$ \\
\hline \multirow{2}{*}{ Sex } & 0.86 & 1.06 & 0.81 & 1.10 & 1.25 & 1.18 \\
\hline & $0.54-1.36$ & $0.88-1.29$ & $0.57-1.16$ & $0.64-1.91$ & $0.89-1.76$ & $0.83-1.68$ \\
\hline \multirow{2}{*}{ Previous stroke } & 0.57 & 0.77 & 0.62 & 0.95 & 1.05 & 0.62 \\
\hline & $0.32-1.02$ & $0.60-0.99$ & $0.40-0.98$ & $0.45-2.00$ & $0.65-1.73$ & $0.18-0.98$ \\
\hline \multirow{2}{*}{ Hypertension } & 1.11 & 0.97 & 1.07 & 0.98 & 0.83 & 1.05 \\
\hline & $0.69-1.80$ & $0.79-1.17$ & $0.76-1.52$ & $0.56-1.71$ & $0.58-1.19$ & $0.71-1.55$ \\
\hline \multirow{2}{*}{ Diabetes mellitus } & 0.82 & 1.03 & 1.07 & 0.86 & 1.11 & 1.02 \\
\hline & $0.48-1.41$ & $0.84-1.27$ & $0.69-1.62$ & $0.38-1.52$ & $0.75-1.64$ & $0.70-1.48$ \\
\hline \multirow{2}{*}{ Previous myocardial infarction } & 1.29 & 1.38 & 1.68 & 1.80 & 1.25 & 1.07 \\
\hline & $0.58-2.86$ & $1.03-1.86$ & $0.96-2.94$ & $0.78-4.17$ & $0.72-2.17$ & $0.60-1.90$ \\
\hline \multirow{2}{*}{ Hypercholesterolemia } & 0.93 & 1.28 & 0.77 & 1.44 & 1.67 & 1.37 \\
\hline & $0.55-1.59$ & $1.03-1.60$ & $0.50-1.20$ & $0.77-2.70$ & $1.10-2.49$ & $0.92-2.10$ \\
\hline \multirow{2}{*}{ Permanent atrial fibrillation } & 1.23 & 0.96 & 0.94 & 1.17 & 0.94 & 1.20 \\
\hline & $0.60-2.56$ & $0.72-1.29$ & $0.64-1.38$ & $0.23-6.06$ & $0.46-1.92$ & $0.47-3.09$ \\
\hline \multirow{2}{*}{ Paroxysmal atrial fibrillation } & 0.35 & 1.70 & 1.60 & 0.93 & 1.32 & 3.45 \\
\hline & $0.14-0.82$ & $1.14-2.55$ & $0.98-2.63$ & $0.10-8.77$ & $0.48-3.61$ & $0.78-15.15$ \\
\hline \multirow{2}{*}{ Prestroke mRS } & 0.67 & 0.94 & 0.85 & 1.14 & 0.75 & 1.25 \\
\hline & $0.41-1.09$ & $0.76-1.15$ & $0.58-1.26$ & $0.62-2.12$ & $0.51-1.09$ & $0.83-1.87$ \\
\hline \multirow{2}{*}{ Admission NIHSS } & 0.98 & 0.99 & 0.99 & 1.02 & 1.00 & 1.01 \\
\hline & $0.97-1.00$ & $0.98-1.00$ & $0.97-1.00$ & $0.99-1.05$ & $0.98-1.02$ & $0.97-1.06$ \\
\hline
\end{tabular}

$\mathrm{mRS}=$ modified Ranking Score; NIHHS = National Institute of Health Stroke Scale; AT = large artery atherosclerotic stroke; CE = cardioembolic stroke; CRY = cryptogenic stroke; LA = lacunar stroke.

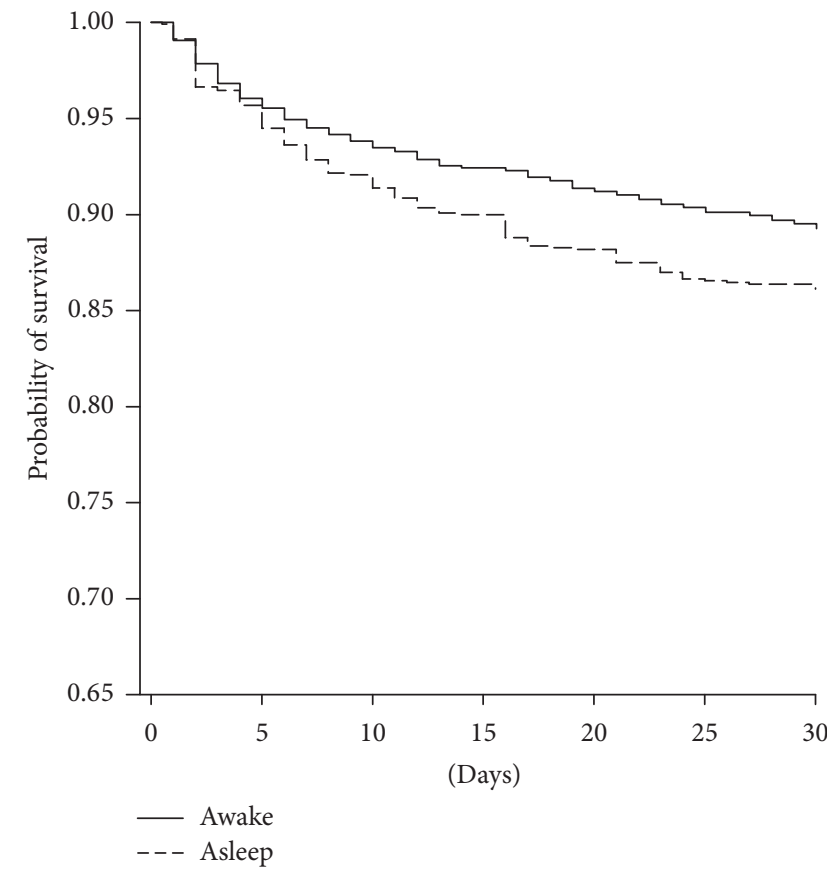

(a)

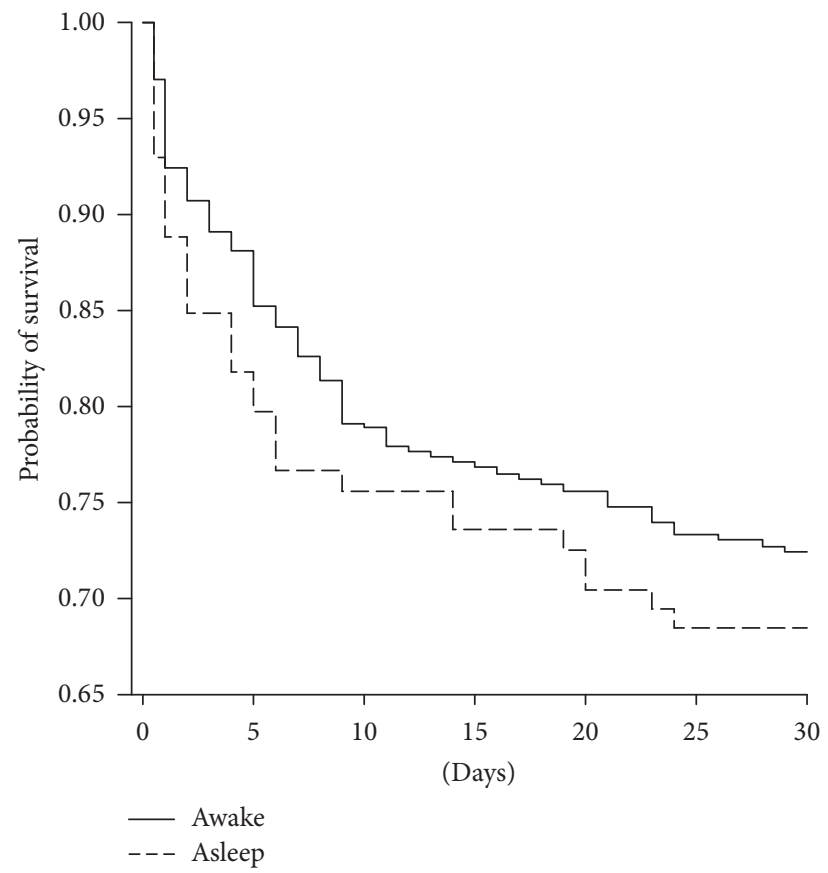

(b)

FIGURE 1: Short-term survival probability (Kaplan-Meier estimates) between awake and asleep onset in (a) ischemic and (b) hemorrhagic stroke. $(\mathrm{a})=p=0.025 ;(\mathrm{b})=\mathrm{ns}$. 
TABLE 4: Multivariate logistic regression among demographic variables and risk factors (both independent variables) with daytime onset in different stroke subtypes. 8-11 versus all other periods (dependent variable).

\begin{tabular}{|c|c|c|c|c|c|}
\hline & Hemorrhagic & $\mathrm{CE}$ & $\mathrm{AT}$ & CRY & LA \\
\hline & \multicolumn{5}{|c|}{ OR 95\% CI } \\
\hline \multirow{2}{*}{ Age } & 0.99 & 1.00 & 1.02 & 1.01 & 0.99 \\
\hline & $0.97-1.02$ & $0.96-1.03$ & $0.98-1.06$ & $0.99-1.02$ & $0.98-1.02$ \\
\hline \multirow{2}{*}{ Sex $(M$ versus $F)$} & 0.81 & 0.93 & 2.66 & 1.09 & 0.92 \\
\hline & $0.48-1.35$ & $0.59-1.47$ & $1.30-5.44$ & $0.72-1.65$ & $0.58-1.46$ \\
\hline \multirow{2}{*}{ Previous stroke } & 0.15 & 1.13 & 0.45 & 1.28 & 1.38 \\
\hline & $0.04-0.50$ & $0.60-2.13$ & $0.18-1.16$ & $0.70-2.32$ & $0.76-2.52$ \\
\hline \multirow{2}{*}{ Hypertension } & 0.80 & 0.88 & 1.92 & 0.82 & 2.25 \\
\hline & $0.47-1.35$ & $0.57-1.37$ & $0.97-3.80$ & $0.53-1.26$ & $1.30-3.88$ \\
\hline \multirow{2}{*}{ Diabetes mellitus } & 1.78 & 1.11 & 1.10 & 1.03 & 0.93 \\
\hline & $0.96-3.30$ & $0.66-1.87$ & $0.52-2.32$ & $0.64-1.65$ & $0.59-1.47$ \\
\hline \multirow{2}{*}{ Previous myocardial infarction } & 0.69 & 0.56 & 0.84 & 0.96 & 0.93 \\
\hline & $0.26-1.82$ & $0.29-1.11$ & $0.31-2.29$ & $0.52-1.79$ & $0.59-1.47$ \\
\hline \multirow{2}{*}{ Hypercholesterolemia } & 1.39 & 1.07 & 0.75 & 1.35 & 0.90 \\
\hline & $0.76-2.55$ & $0.62-1.84$ & $0.36-1.57$ & $0.85-2.14$ & $0.55-1.46$ \\
\hline \multirow{2}{*}{ Permanent atrial fibrillation } & 1.42 & 1.37 & 0.11 & 0.69 & 2.48 \\
\hline & $0.60-3.37$ & $0.84-2.20$ & $0.01-1.32$ & $0.24-2.03$ & $0.91-6.77$ \\
\hline \multirow{2}{*}{ Paroxysmal atrial fibrillation } & 0.54 & 1.15 & \multirow{2}{*}{$\mathrm{NE}$} & 0.18 & 0.93 \\
\hline & $0.10-2.85$ & $0.66-2.01$ & & $0.02-1.42$ & $0.31-2.75$ \\
\hline \multirow{2}{*}{ Prestroke mRS } & 1.12 & 1.28 & 2.15 & 1.28 & 0.86 \\
\hline & $0.64-1.95$ & $0.77-2.13$ & $0.94-4.92$ & $0.79-2.08$ & $0.53-1.41$ \\
\hline \multirow{2}{*}{ Admission NIHSS } & 1.01 & 1.01 & 0.98 & 0.96 & 1.03 \\
\hline & $0.99-4.99$ & $0.99-1.04$ & $0.01-3.05$ & $0.94-0.99$ & $0.97-1.08$ \\
\hline
\end{tabular}

$\mathrm{NE}=$ not estimable for lack of cases in at least one condition. $\mathrm{mRS}=$ modified Ranking Score; NIHHS = National Institute of Health Stroke Scale. AT $=$ large artery atherosclerotic stroke; $\mathrm{CE}=$ cardioembolic stroke; $\mathrm{CRY}=$ cryptogenic stroke; $\mathrm{LA}=$ lacunar stroke.

Different physiological and pathological factors and different lifestyles may be responsible for and influence the onset of stroke during sleep or waking. In particular, patients with ischemic stroke that occurred during sleep were more likely to have had at least one previous stroke and to be older than patients with ischemic stroke that occurred during waking. On the contrary, in patients with a concomitant cardiovascular disease, as shown by hypercholesterolemia, previous myocardial infarction, and atrial fibrillation, the onset of ischemic stroke is likely to occur during waking.

Moreover, our study suggests, for the first time, that the time of stroke occurrence may correlate with prognosis and outcome, with differences between ischemic and hemorrhagic stroke. Patients with ischemic stroke that occurred during sleep display a worse disability level at hospital discharge compared to ischemic stroke occurred during waking and have a higher risk of death during the first month. However, no difference in the prestroke disability presence was observed. Discharge disability score was strongly due to fibrinolysis therapy performed in about $10 \%$ of awake onset $\mathrm{CE}$ and CRY patients. However, 30-day mortality was not influenced by fibrinolysis therapy. Our data on worse discharge disability and great mortality risk in ischemic stroke occurring during sleep are in agreement with published data [22] but we added the new information that, in ischemic stroke, this is true only for the CE group.
Hemorrhagic stroke patients with awake onset showed a worse disability level at hospital discharge but the 30day mortality was not significantly different compared to asleep onset. Our data did not agree with published data in which authors suggested worse conditions in hemorrhagic stroke with asleep compared to awake onset [11]. However, the latter is performed on a small number of patients. A recent multicenter study reports that patients arriving in the emergency department at night or in the morning with "idiopathic" intraparenchymal hemorrhage had higher inhospital mortality than those arriving in the afternoon [38]. Our data show a slight even if not significant increase of mortality at one month from stroke, but, as can be observed in Figure 1(b), an increase in mortality during the first and possibly in-hospital period can be suggested in our patients too.

Awake/asleep onset seems to influence prognosis in different ways in hemorrhagic and ischemic stroke since awake onset influences negatively discharge disability in hemorrhagic and positively in ischemic stroke. We observed that in our ischemic patients this is due to fibrinolysis therapy. Moreover, in the same ischemic patients we found a lower mortality during the first month after stroke in awake onset irrespective of fibrinolysis therapy.

Therefore, a new interesting feature was that awake/asleep onset seems to be in some way associated with outcome. To 


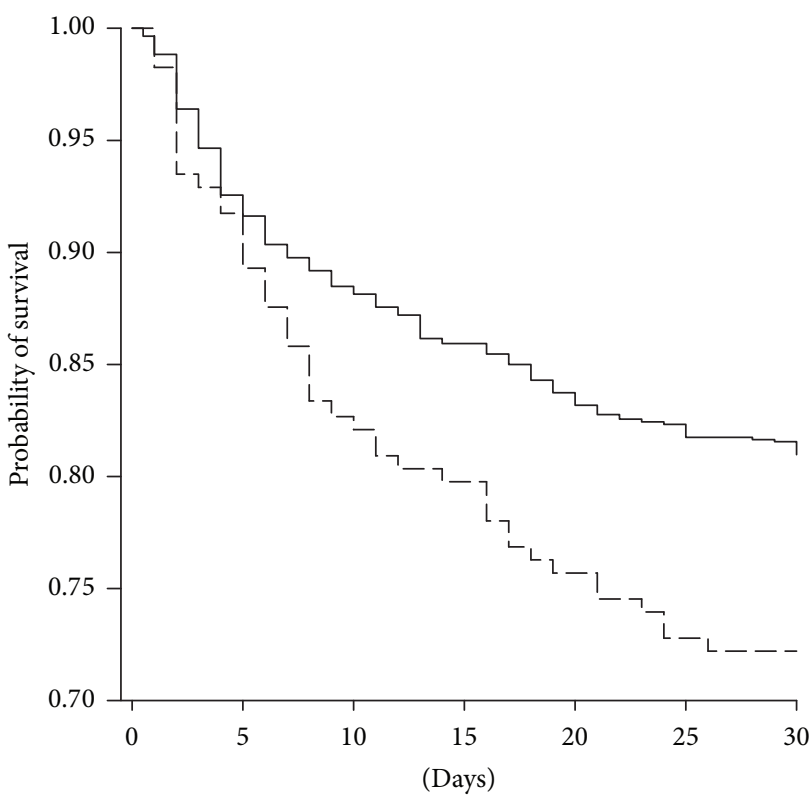

- Awake

--- Asleep

(a)

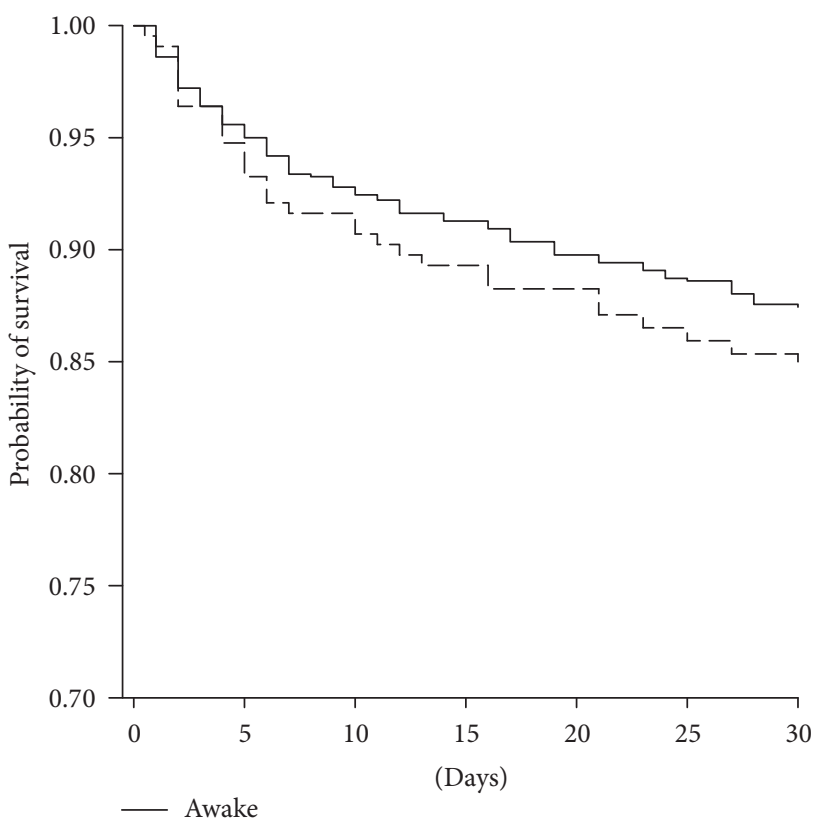

(c)

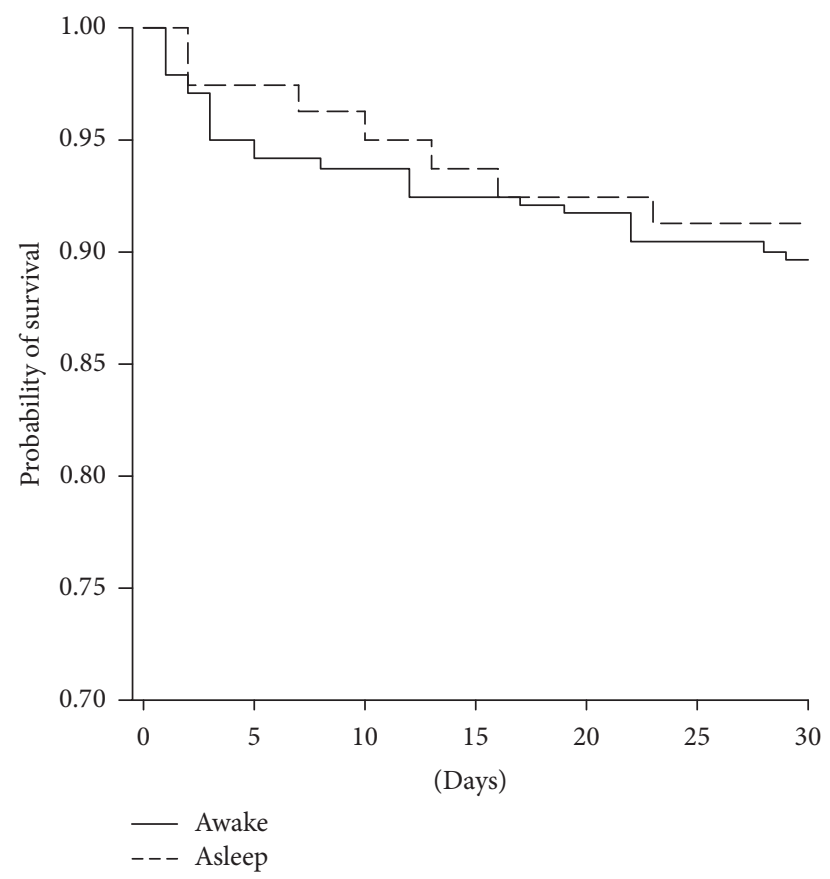

(b)

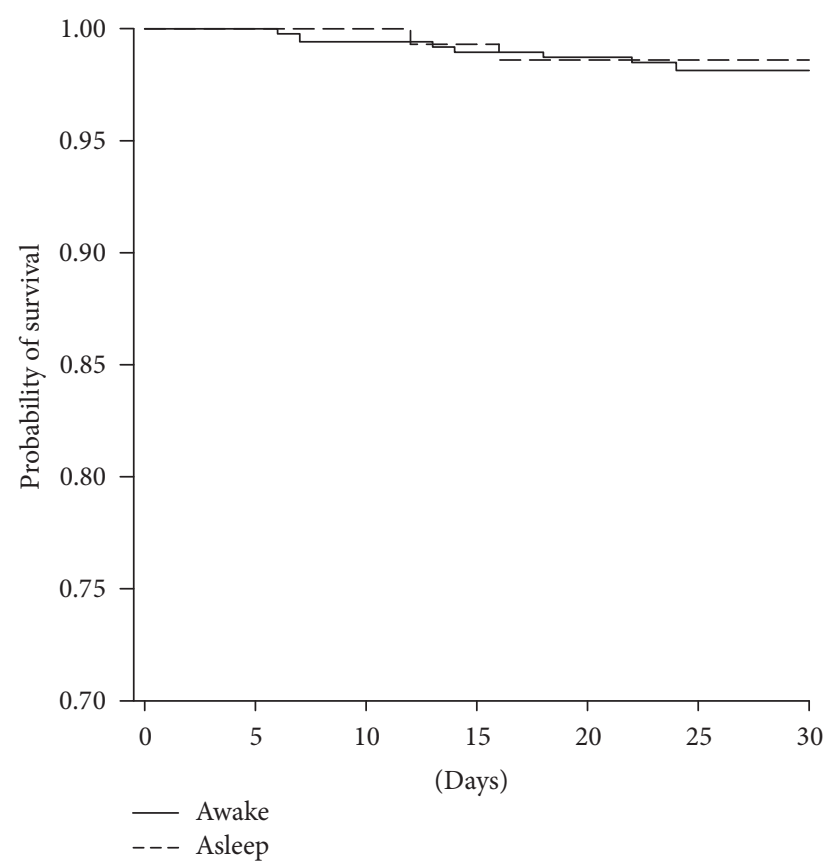

(d)

FIGURE 2: Short-term survival probability (Kaplan-Meier estimates) between awake and asleep onset in (a) CE, (b) AT, (c) CRY, and (d) LA stroke. $(\mathrm{a})=p=0.01$ and $(\mathrm{b})$, (c), and $(\mathrm{d})=\mathrm{ns}$.

our knowledge this is the first report showing a correlation between outcome and awake/asleep time of occurrence in stroke subgroups.

As concerns the diurnal pattern of onset, our findings are consistent with previous studies [2,3] in observing that stroke onset had a diurnal pattern even when controlling for other considered variables. In all strokes there is a significantly higher risk of occurrence in the morning and a lower risk in the late afternoon. This is also true in hemorrhagic stroke, in which this pattern is controversially discussed in the literature. In particular all subtypes of studied stroke occur preferably in the first few hours after awakening in accordance with many authors (Table 1). Some authors have reported two peaks of onset, one in the morning and the 


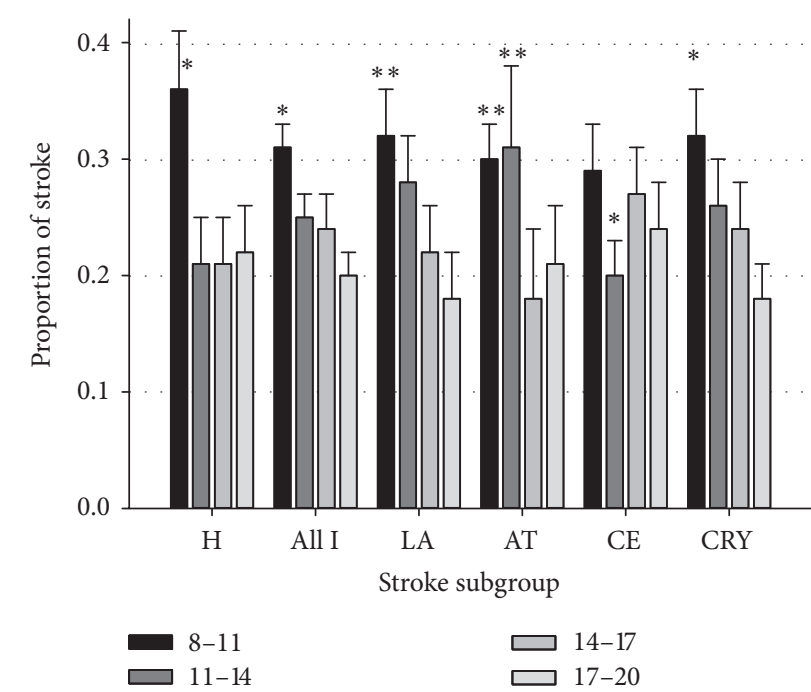

FIgURE 3: Proportion of stroke onset during diurnal period in subgroups of stroke. $\mathrm{H}$, hemorrhagic; all I, all ischemic; LA; AT; CE; CRY. Black bars = 8-11; dark gray bars $=11-14$; gray bars $=14-17$; light gray bars $=17-20 . *$ indicates at least $p<0.005$ from other intervals; $* *$ indicates at least $p<0.01$ from afternoon intervals.

other in the afternoon for some subtype of strokes [2, 4$6,8,19,20,25,29,32,34,35]$ but our data did not confirm this hypothesis. In the same way we did not confirm data on higher night onset in some subgroups as reported by other, few, authors [23, 39-42]. Moreover, we observed a specific diurnal time pattern in each stroke subgroup. Previous data considering onset time in specific subgroups of patient were discordant and were performed on a small group of patients; our study contributes useful information.

It is interesting to note that, in hemorrhagic stroke patients, the fact of having had at least one previous stroke seems to be protective for the early morning onset compared to other diurnal periods, while hypercholesterolemia seems to favor stroke during the morning and early afternoon compared to the late afternoon. However, since these data are not corrected for oral anticoagulant and anticholesterol therapies, no conclusions can be drawn. Sex influenced diurnal onset. Males suffered significantly more frequently from stroke in the early morning than in the afternoon, while on the contrary females were less affected in the early morning than in the afternoon.

In LA patients, in which hypertension is an important predisposing factor, being normotensive protects patients from developing stroke during the highly at-risk awake period.

The pattern we observed in these cerebrovascular accidents has already been observed in other acute cardiovascular events [50-56]. This pattern parallels the reported diurnal variation in blood pressure [57], which is higher in the morning, and higher blood pressure is accepted as a risk factor for stroke. Other different risk factors such as coagulability, epinephrine and norepinephrine, and alphasympathetic vasoconstriction are higher in the morning [6, 58]. Moreover, platelet aggregation increases significantly in the morning during the assumption of an upright posture and when beginning the daily activities $[59,60]$. Daily variability in stroke occurrence can reflect autonomic nervous system modulations and even more its modifications with aging, which is suspected to facilitate stroke. Vagal tonic modulation during the night, in fact, is higher in young males and decreases with aging and it has been associated with stroke risk $[61,62]$. These differences may partially justify the different circadian distribution of stroke onset between males and females and during aging. Our data suggest that the daily occurrence of stroke is significantly influenced by the circadian clock that determines biorhythms, the circadian fluctuations of vital and physiological parameters, and the subjects' activities.

Also other recurrent critical events in other diseases, not necessarily vascular ones, such as chronic airway disease [63], rheumatoid arthritis [64], allergic rhinitis [64], epileptic seizures [60], headache attacks [65], and psychiatric disorders [66] among others, may be affected by internal biorhythms. The roles played by the circadian clock in pathologies deserve to be studied more extensively and possibly to be given better consideration for prophylaxis and treatment purposes.

\section{Limitations}

The present study has different limitations. It is a retrospective study based on data collected during hospitalization that included only patients with AT, CE, CRY, LA, or intracerebral hemorrhage stroke and thus information on other etiologies is lacking. The main limitation of this study was, however, not having considered some factors such as therapy taken before and during hospitalization, presence of disruption of circadian rhythms, subjects' activities, or other circumstances temporally close to the stroke onset as the possible effect of nocturnal blood pressure and the extreme seasonal and house humidity and temperature.

\section{Conclusions}

Our study has the strength of considering the stroke onset in relation to patient characteristics in a large cohort of patients drawn from a well-defined catchment area. An advantage is that we considered all consecutive patients admitted to a Stroke Unit over a period of 10 years. In all cases considered there was indication of precise stroke onset and if it was reported on awakening we considered it as asleep onset. Thus, we were able to consider stroke onset in relation to waking/sleep alternation as well.

Our study confirms that stroke as many other cardiovascular diseases occurs preferentially during waking and in the morning irrespective of the subtype. We observed that some risk factors are associated with time of stroke onset, suggesting that they interact with biorhythms in inducing stroke. In this context, strategies considering the specific treatment of risk factors during the circadian period of their major influence on stroke onset may ameliorate preventive and therapeutic interventions. Further efforts to study the specific aspects of circadian rhythms on cerebrovascular disease are 
needed to better understand the pathophysiological features and to obtain beneficial effects in terms of prevention and treatment.

\section{Ethical Approval}

This study was approved by the local ethical committee (Approval 272/CE, Project 16021).

\section{Conflicts of Interest}

The authors declared no potential conflicts of interest with respect to the research, authorship, and/or publication of this article.

\section{Authors' Contributions}

Luciana Ripamonti, Roberto Riva, and Gaetano Procaccianti conceived the study, were involved in the protocol development, interpreted the data, and wrote the manuscript. Luciana Ripamonti, Roberto Riva, Fabiola Maioli, and Gaetano Procaccianti were involved in patient recruitment and acquisition of data. Luciana Ripamonti, Roberto Riva, and Corrado Zenesini performed the data analysis. All authors reviewed and approved the final version of the manuscript.

\section{Acknowledgments}

The authors wish to acknowledge Cecilia Baroncini for help in the English revision of the text. They disclosed receipt of the following financial support for the research, authorship, and/or publication of this article: this work was supported by the Italian Ministry of Health.

\section{References}

[1] R. Manfredini, M. Gallerani, F. Portaluppi, R. Salmi, and C. Fersini, "Chronobiological patterns of onset of acute cerebrovascular diseases," Thrombosis Research, vol. 88, no. 6, pp. 451-463, 1997.

[2] R. Manfredini, B. Boari, M. H. Smolensky et al., "Circadian variation in stroke onset: Identical temporal pattern in ischemic and hemorrhagic events," Chronobiology International, vol. 22, no. 3, pp. 417-453, 2005.

[3] W. J. Elliott, "Circadian variation in the timing of stroke onset: a meta-analysis," Stroke, vol. 29, no. 5, pp. 992-996, 1998.

[4] G. S. Stergiou, K. N. Vemmos, K. M. Pliarchopoulou, A. G. Synetos, L. G. Roussias, and T. D. Mountokalakis, "Parallel morning and evening surge in stroke onset, blood pressure, and physical activity," Stroke, vol. 33, no. 6, pp. 1480-1486, 2002.

[5] I. Casetta, E. Granieri, E. Fallica, O. La Cecilia, E. Paolino, and R. Manfredini, "Patient demographic and clinical features and circadian variation in onset of ischemic stroke," Archives of Neurology, vol. 59, no. 1, pp. 48-53, 2002.

[6] S. Omama, Y. Yoshida, A. Ogawa, T. Onoda, and A. Okayama, "Differences in circadian variation of cerebral infarction, intracerebral haemorrhage and subarachnoid haemorrhage by situation at onset," Journal of Neurology, Neurosurgery and Psychiatry, vol. 77, no. 12, pp. 1345-1349, 2006.
[7] T. Inagawa, A. Takechi, K. Tahara et al., "Primary intracerebral and aneurysmal subarachnoid hemorrhage in Izumo City, Japan. Part I: Incidence and seasonal and diurnal variations," Journal of Neurosurgery, vol. 93, no. 6, pp. 958-966, 2000.

[8] M. U. Butt, M. Zakaria, and H. M. Hussain, "Circadian pattern of onset of ischaemic and haemorrhagic strokes, and their relation to sleep/wake cycle," Journal of Pakistan Medical Association, vol. 59, pp. 129-132, 2009.

[9] S. Chaturvedi, H. P. Adams Jr., and R. F. Woolson, "Circadian variation in ischemic stroke subtypes," Stroke, vol. 30, no. 9, pp. 1792-1795, 1999.

[10] S. Passero, F. Reale, G. Ciacci, and E. Zei, "Differing temporal patterns of onset in subgroups of patients with intracerebral hemorrhage," Stroke, vol. 31, no. 7, pp. 1538-1544, 2000.

[11] Y. Nagakane, K. Miyashita, K. Nagatsuka, T. Yamawaki, and H. Naritomi, "Primary intracerebral hemorrhage during asleep period," American Journal of Hypertension, vol. 19, no. 4, pp. 403-406, 2006.

[12] N. Anderson, V. Feigin, D. Bennett et al., "Diurnal, weekly, and seasonal variations in stroke occurrence in a populationbased study in Auckland, New Zealand," New Zealand Medical Journal, vol. 117, no. 1202, 2004.

[13] M. S. Uddin, M. I. Hoque, M. K. Uddin, S. A. Kamol, and R. H. Chowdhury, "Circadian Rhythm of onset stroke in 50 cases of ischemic stroke," Mymensingh Medical Journal, vol. 24, no. 1, pp. 121-126, 2015.

[14] H. Naess, T. Idicula, J. Brogger, U. Waje-Andreassen, and L. Thomassen, "High proportion of lacunar strokes at night: the bergen stroke study," Journal of Stroke and Cerebrovascular Diseases, vol. 20, no. 5, pp. 424-428, 2011.

[15] A. Lago, D. Geffner, J. Tembl, L. Landete, C. Valero, and M. Baquero, "Circadian variation in acute ischemic stroke: a hospital-based study," Stroke, vol. 29, no. 9, pp. 1873-1875, 1998.

[16] K. Spengos, G. Tsivgoulis, E. Manios et al., "Stroke etiology is associated with symptom onset during sleep," Sleep, vol. 28, no. 2, pp. 233-238, 2005.

[17] N. M. Bornstein, A. Y. Gur, P. Fainshtein, and A. D. Korczyn, "Stroke during sleep: epidemiological and clinical features," Cerebrovascular Diseases, vol. 9, no. 6, pp. 320-322, 1999.

[18] R. T. F. Cheung, W. Mak, and K. H. Chan, "Circadian variation of stroke onset in Hong Kong Chinese: A hospital-based study," Cerebrovascular Diseases, vol. 12, no. 1, pp. 1-6, 2001.

[19] K. Spengos, K. N. Vemmos, G. Tsivgoulis et al., “Two-peak temporal distribution of stroke onset in Greek patients: a hospital-based study," Cerebrovascular Diseases, vol. 15, no. 1-2, pp. 70-77, 2003.

[20] K. Spengos, K. Vemmos, G. Tsivgoulis et al., "Diurnal and seasonal variation of stroke incidence in patients with cardioembolic stroke due to atrial fibrillation," Neuroepidemiology, vol. 22, no. 3, pp. 204-210, 2003.

[21] T. C. Turin, Y. Kita, N. Rumana et al., "Wake-up stroke: incidence, risk factors and outcome of acute stroke during sleep in a japanese population. takashima stroke registry 1988-2003," European Neurology, vol. 69, no. 6, pp. 354-359, 2013.

[22] J. Jiménez-Conde, A. Ois, A. Rodríguez-Campello, M. Gomis, and J. Roquer, "Does sleep protect against ischemic stroke? less frequent ischemic strokes but more severe ones," Journal of Neurology, vol. 254, no. 6, pp. 782-788, 2007.

[23] A. Kocer, A. Ilhan, N. Ince, and C. Bilge, "The related causes in very early morning onset of stroke," Progress in NeuroPsychopharmacology and Biological Psychiatry, vol. 29, no. 6, pp. 983-988, 2005. 
[24] P. A. Nyquist, R. D. Brown Jr., D. O. Wiebers, C. S. Crowson, and W. M. O'Fallon, "Circadian and seasonal occurrence of subarachnoid and intracerebral hemorrhage," Neurology, vol. 56, no. 2, pp. 190-193, 2001.

[25] J. Feng, J. H. Zhang, and X. Qin, "Timing pattern of onset in hypertensive intracerebral hemorrhage patients," Acta Neurochirurgica, Supplementum, no. 111, pp. 327-331, 2011.

[26] Y. I. Choi, I.-K. Seo, D.-E. Kim et al., "Same pattern of circadian variation according to the season in the timing of ischemic stroke onset: preliminary report," Sleep Medicine Research, vol. 6, no. 2, pp. 72-76, 2015.

[27] D. M. Fodor, I. Babiciu, and L. Perju-Dumbrava, "Circadian variation of stroke onset: a hospital-based study," Clujul Medical, vol. 87, no. 4, p. 8, 2014.

[28] D. M. Fodor, D. Gonganau-Nitu, and L. Perju-Dumbrava, "Circadian pattern of ischemic stroke onset," in Human Vet Med Bioflux, vol. 6, pp. 132-139, 2014.

[29] T. Inagawa, "Diurnal and seasonal variations in the onset of primary intracerebral hemorrhage in individuals living in Izumo City, Japan," Journal of Neurosurgery, vol. 98, no. 2, pp. 326-336, 2003.

[30] J. Serena, A. Dávalos, T. Segura, E. Mostacero, and J. Castillo, "Stroke on awakening: Looking for a more rational management," Cerebrovascular Diseases, vol. 16, no. 2, pp. 128-133, 2003.

[31] C. Bassetti and M. Aldrich, "Night time versus daytime transient ischaemic attack and ischaemic stroke: A prospective study of 110 patients," Journal of Neurology Neurosurgery and Psychiatry, vol. 67, no. 4, pp. 463-467, 1999.

[32] T. C. Turin, Y. Kita, N. Rumana et al., "Morning surge in circadian periodicity of ischaemic stroke is independent of conventional risk factor status: findings from the takashima stroke registry 1990-2003," European Journal of Neurology, vol. 16, no. 7, pp. 843-851, 2009.

[33] S. A. Tsementzis, J. S. Gill, E. R. Hitchcock, and D. G. Beevers, "Diurnal variation of and activity during the onset of stroke," Neurosurgery, vol. 17, no. 6, pp. 901-904, 1985.

[34] S. J. Wroe, P. Sandercock, J. Bamford, M. Dennis, J. Slattery, and C. Warlow, "Diurnal variation in incidence of stroke: oxfordshire community stroke project," British Medical Journal, vol. 304, no. 6820, pp. 155-157, 1992.

[35] M. A. Sloan, T. R. Price, M. A. Foulkes et al., "Circadian rhythmicity of stroke onset intracerebral and subarachnoid hemorrhage," Stroke, vol. 23, no. 10, pp. 1420-1426, 1992.

[36] C. Argentino, D. Toni, M. Rasura et al., "Circadian variation in the frequency of ischemic stroke," Stroke, vol. 21, no. 3, pp. 387$389,1990$.

[37] J. N. Fink, S. Kumar, C. Horkan et al., “The stroke patient who woke up clinical and radiological features, including diffusion and perfusion MRI," Stroke, vol. 33, no. 4, pp. 988-993, 2002.

[38] F. Fabbian, R. Manfredini, A. De Giorgi et al., “'Timing' of arrival and in-hospital mortality in a cohort of patients under anticoagulant therapy presenting to the emergency departments with cerebral hemorrhage: a multicenter chronobiological study in Italy," Chronobiology International, vol. 33, no. 3, pp. 245-256, 2016.

[39] J. Marshall, "Diurnal variation in occurrence of strokes," Stroke, vol. 8, no. 2, pp. 230-231, 1977.

[40] L. R. Caplan, D. B. Hier, and I. D’Cruz, "Cerebral embolism in the Michael Reese stroke registry," Stroke, vol. 14, no. 4, pp. 530536, 1983.
[41] A. Arboix and J. L. Martí-Vilalta, "Acute stroke and circadian rhythm," Stroke, vol. 21, no. 5, p. 826, 1990.

[42] V. Hossmann, "Circadian changes of blood pressure and stroke," in Cerebral Circulation and Stroke, K. J. Zulch, Ed., pp. 203-208, Springer, Berlin, Germany, 1971.

[43] P. Pasqualetti, G. Natali, R. Casale, and D. Colantonio, "Epidemiological chronorisk of stroke," Acta Neurologica Scandinavica, vol. 81, no. 1, pp. 71-74, 1990.

[44] J. R. Marler, T. R. Price, G. L. Clark et al., "Morning increase in onset of ischemic stroke," Stroke, vol. 20, no. 4, pp. 473-476, 1989.

[45] E. E. Marsh, J. Biller, H. P. Adams et al., "Circadian variation in onset of acute ischemic stroke," Archives of Neurology, vol. 47, no. 11, pp. 1178-1180, 1990.

[46] S. Ricci, M. Grazia Celani, R. Vitali, F. La Rosa, E. Righetti, and E. Duca, "Diurnal and seasonal variations in the occurrence of stroke: a community-based study," Neuroepidemiology, vol. 11, no. 2, pp. 59-64, 1992.

[47] J. Rankin, "Cerebral vascular accidents in patients over the age of 60. II. Prognosis," Scottish Medical Journal, vol. 2, no. 5, pp. 200-215, 1957

[48] B. Farrell, J. Godwin, S. Richards, and C. Warlow, "The United Kingdom transient ischaemic attack (UK-TIA) aspirin trial: final results," Journal of Neurology Neurosurgery and Psychiatry, vol. 54, no. 12, pp. 1044-1054, 1991.

[49] Stata Corp. 2015. Stata Statistical Software: Release 14. College Station, TX: Stata Corp LP.

[50] V. Shanmugam, A. Wafi, N. AlTaweel, and D. Büsselberg, "Circadian variation and triggering of cardiovascular events," Vascular Medicine, vol. 4, pp. 41-49, 1999.

[51] V. Shanmugam, A. Wafi, N. Al-Taweel, and D. Büsselberg, "Disruption of circadian rhythm increases the risk of cancer, metabolic syndrome and cardiovascular disease," Journal of Local and Global Health Science, vol. 3, 2013.

[52] A. Capucci, G. Calcagnini, E. Mattei et al., "Daily distribution of atrial arrhythmic episodes in sick sinus syndrome patients: Implications for atrial arrhythmia monitoring," Europace, vol. 14, no. 8, pp. 1117-1124, 2012.

[53] S. Viskin, M. Golovner, N. Malov et al., "Circadian variation of symptomatic paroxysmal atrial fibrillation; data from almost 10,000 episodes," European Heart Journal, vol. 20, no. 19, pp. 1429-1434, 1999.

[54] J. E. Muller, G. H. Tofler, and P. H. Stone, "Circadian variation and triggers of onset of acute cardiovascular disease," Circulation, vol. 79, no. 4, pp. 733-743, 1989.

[55] J. E. Muller, P. H. Stone, Z. G. Turi et al., "Circadian variation in the frequency of onset of acute myocardial infarction," The New England Journal of Medicine, vol. 313, no. 21, pp. 1315-1322, 1985.

[56] M. C. Cohen, K. M. Rohtla, C. E. Lavery, J. E. Muller, and M. A. Mittleman, "Meta-analysis of the morning excess of acute myocardial infarction and sudden cardiac death," American Journal of Cardiology, vol. 79, no. 11, pp. 1512-1516, 1997.

[57] G. D. James, T. Toledano, G. Datz, and T. G. Pickering, "Factors influencing the awake-sleep difference in ambulatory blood pressure: main effects and sex differences," Journal of Human Hypertension, vol. 9, no. 10, pp. 821-826, 1995.

[58] J. A. Panza, S. E. Epstein, and A. A. Quyyumi, "Circadian variation in vascular tone and its relation to $\alpha$-sympathetic vasoconstrictor activity," New England Journal of Medicine, vol. 325, no. 14, pp. 986-990, 1991. 
[59] D. A. Brezinski, G. H. Tofler, J. E. Muller et al., "Morning increase in platelet aggregability. Association with assumption of the upright posture," Circulation, vol. 78, no. 1, pp. 35-40, 1988.

[60] G. H. Tofler, D. Brezinski, A. I. Schafer et al., "Concurrent morning increase in platelet aggregability and the risk of myocardial infarction and sudden cardiac death," New England Journal of Medicine, vol. 316, no. 24, pp. 1514-1518, 1987.

[61] Z. Binici, M. R. Mouridsen, L. Køber, and A. Sajadieh, "Decreased nighttime heart rate variability is associated with increased stroke risk," Stroke, vol. 42, no. 11, pp. 3196-3201, 2011.

[62] H. Bonnemeier, U. K. H. Wiegand, A. Brandes et al., "Circadian profile of cardiac autonomic nervous modulation in healthy subjects: differing effects of aging and gender on heart rate variability," Journal of Cardiovascular Electrophysiology, vol. 14, no. 8, pp. 791-799, 2003.

[63] I. K. Sundar, H. Yao, M. T. Sellix, and I. Rahman, "Circadian clock-coupled lung cellular and molecular functions in chronic airway diseases," American Journal of Respiratory Cell and Molecular Biology, vol. 53, no. 3, pp. 285-290, 2015.

[64] M. Cutolo and A. T. Masi, "Circadian rhythms and arthritis," Rheumatic Disease Clinics of North America, vol. 31, no. 1, pp. 115-129, 2005.

[65] T. Pringsheim, "Cluster headache: evidence for a disorder of circadian rhythm and hypothalamic function," Canadian Journal of Neurological Sciences, vol. 29, no. 1, pp. 33-40, 2002.

[66] I. N. Karatsoreos, "Links between circadian rhythms and psychiatric disease," Frontiers in Behavioral Neuroscience, vol. 8, article 162, 2014. 


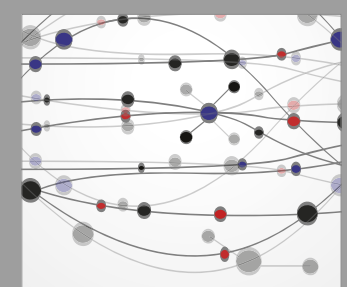

The Scientific World Journal
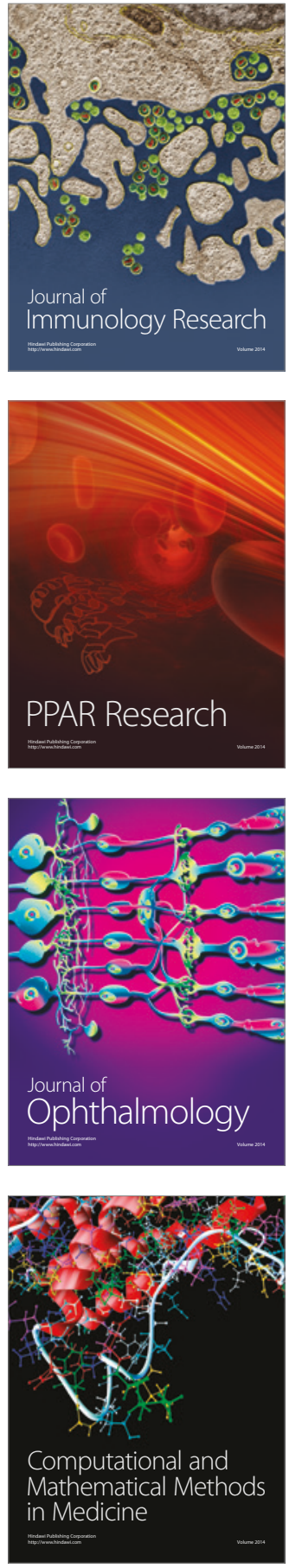

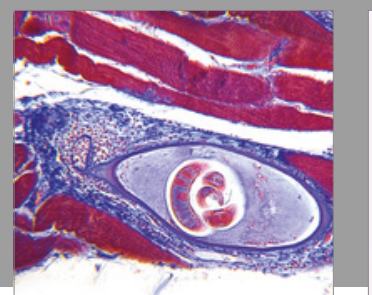

Gastroenterology Research and Practice
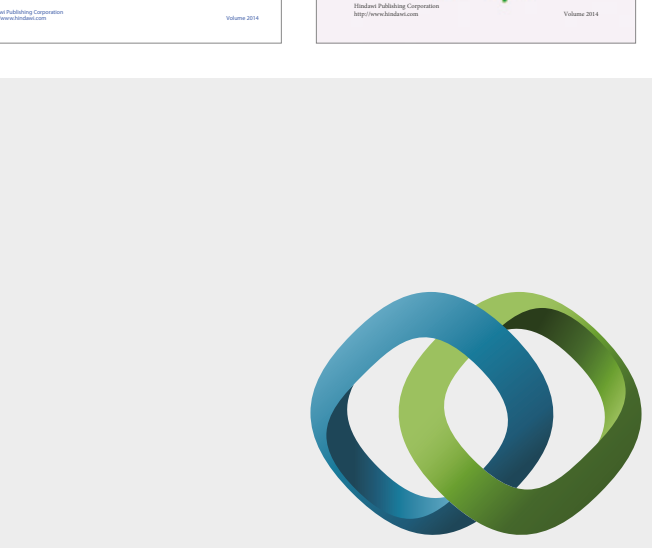

\section{Hindawi}

Submit your manuscripts at

https://www.hindawi.com
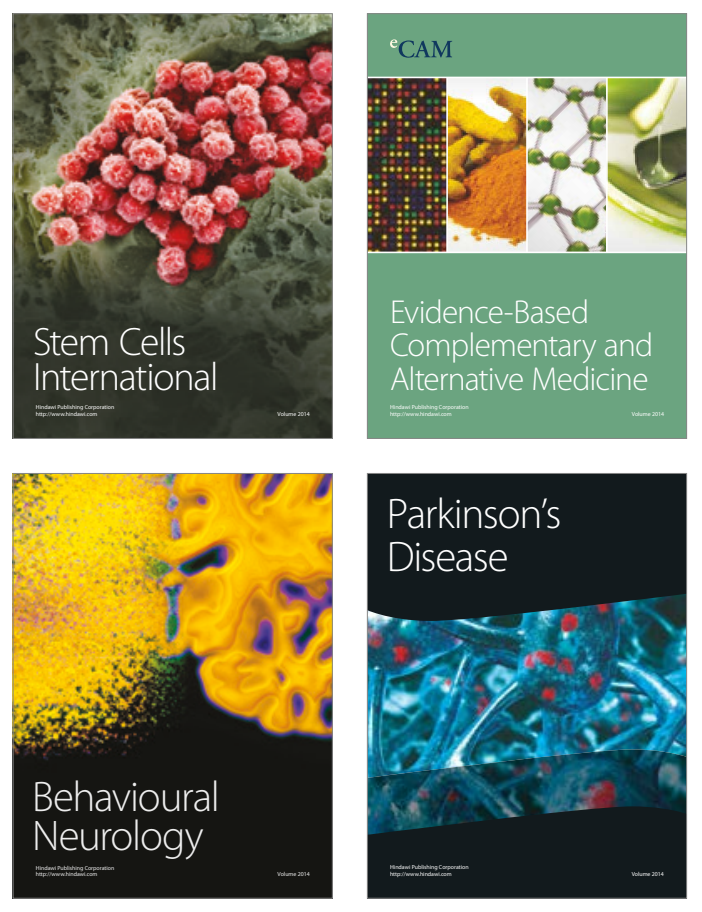
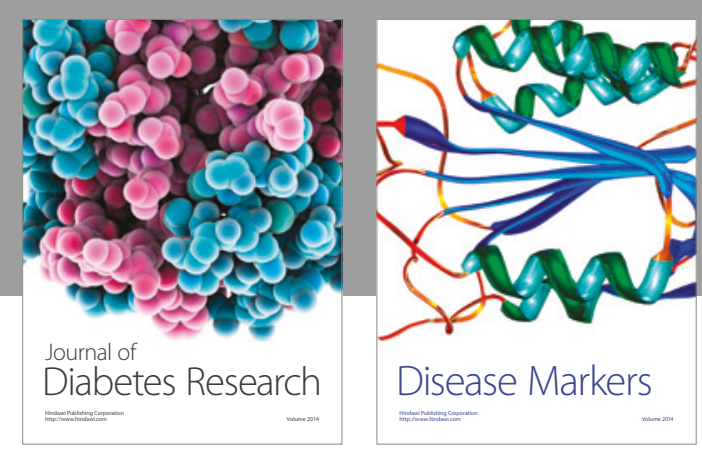

Disease Markers
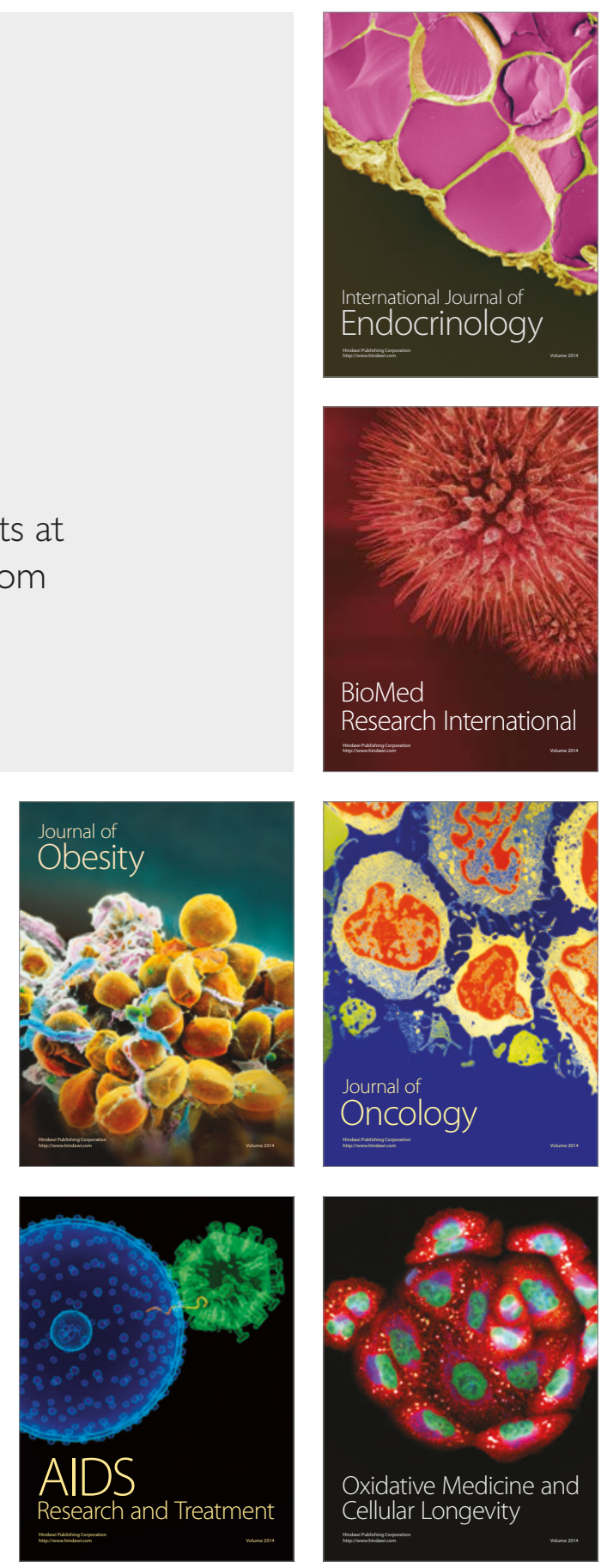